\title{
Data Mining: A prediction for Student's Performance Using Classification Method
}

\author{
Abeer Badr El Din Ahmed ${ }^{1}$, Ibrahim Sayed Elaraby, ${ }^{2, *}$ \\ ${ }^{1}$ Lecturer at Sadat Academy, Computer Science Department, Cairo, Egypt \\ ${ }^{2}$ Demonstrator at Higher Institute for Specific Studies, Management Information System Department, Cairo, Egypt \\ *Corresponding Author: oe_2010@yahoo.com
}

Copyright (C) 2014 Horizon Research Publishing All rights reserved.

\begin{abstract}
Currently the amount huge of data stored in educational database these database contain the useful information for predict of students performance. The most useful data mining techniques in educational database is classification. In this paper, the classification task is used to predict the final grade of students and as there are many approaches that are used for data classification, the decision tree (ID3) method is used here.
\end{abstract}

Keywords Educational Data Mining (EDM), Classification, Knowledge Discovery in Database (KDD), ID3 Algorithm.

\section{Introduction}

The advent of information technology in various fields has lead the large volumes of data storage in various formats like records, files, documents, images, sound, videos, scientific data and many new data formats. The data collected from different applications require proper method of extracting knowledge from large repositories for better decision making. Knowledge discovery in databases (KDD), often called data mining, aims at the discovery of useful information from large collections of data [1]. The main functions of data mining are applying various methods and algorithms in order to discover and extract patterns of stored data [2].

The main objective of this paper is to use data mining methodologies to study student's performance in end General appreciation. Data mining provides many tasks that could be used to study the student performance. In this research, the classification task is used to evaluate student's performance and as there are many approaches that are used for data classification, the decision tree method is used here.

\section{Related Work}

Han and Kamber (1996) [3] describes data mining software that allow the users to analyze data from different dimensions, categorize it and summarize the relationships which are identified during the mining process.

Brijesh Kumar Baradwaj and Saurabh Pal (2011) [1] describes the main objective of higher education institutions is to provide quality education to its students. One way to achieve highest level of quality in higher education system is by discovering knowledge for prediction regarding enrolment of students in a particular course, detection of abnormal values in the result sheets of the students, prediction about students' performance and so on, the classification task is used to evaluate student's performance and as there are many approaches that are used for data classification, the decision tree method is used here.

Alaa El-Halees (2009) [4] applied the educational data mining concerns with developing methods for discovering knowledge from data that come from educational environment. used educational data mining to analyze learning behavior. Student's data has been collected from Database course. After preprocessing the data, we applied data mining techniques to discover association, classification, clustering and outlier detection rules. In each of these four tasks, we extracted knowledge that describes students' behavior.

Mohammed M. Abu Tair and Alaa M. El-Halees (2012) [5] applied the educational data mining concerns with developing methods for discovering knowledge from data that come from educational domain. used educational data mining to improve graduate students' performance, and overcome the problem of low grades of graduate students and try to extract useful knowledge from graduate students data collected from the college of Science and Technology. The data include fifteen years period [1993-2007]. After preprocessing the data, we applied data mining techniques to discover association, classification, clustering and outlier detection rules. In each of these four tasks, we present the extracted knowledge and describe its importance in educational domain.

Sonali Agarwal, G. N. Pandey, and M. D. Tiwari (2012) [6] describes the educational organizations are one of the important parts of our society and playing a vital role for growth and development of any nation. Data Mining is an 
emerging technique with the help of this one can efficiently learn with historical data and use that knowledge for predicting future behavior of concern areas. Growth of current education system is surely enhanced if data mining has been adopted as a futuristic strategic management tool. The Data Mining tool is able to facilitate better resource utilization in terms of student performance, course development and finally the development of nation's education related standards.

Monika Goyal and Rajan Vohra (2012) [7] applied data mining techniques to improve the efficiency of higher education institution. If data mining techniques such as clustering, decision tree and association are applied to higher education processes, it would help to improve students' performance, their life cycle management, selection of courses, to measure their retention rate and the grant fund management of an institution. This is an approach to examine the effect of using data mining techniques in higher education.

Surjeet Kumar Yadav, Brijesh Bharadwaj, and Saurabh Pal (2012) [11] used decision tree classifiers are studied and the experiments are conducted to find the best classifier for retention data to predict the student's drop-out possibility.

Brijesh Kumar Baradwaj and Saurabh Pal (2011) [12] Used the classification task on student database to predict the students division on the basis of previous database.

K.Shanmuga Priya and A.V.Senthil Kumar (2013) [13] applied a Classification Technique in Data Mining to improve the student's performance and help to achieve the goal by extracting the discovery of knowledge from the end semester mark.

Bhise R.B, Thorat S.S and Supekar A.K. (2013) [14] used data mining process in a student's database using K-means clustering algorithm to predict students result.

Varun Kumar and Anupama Chadha (2013) [15] used of one of the data mining technique called association rule mining in enhancing the quality of students' performances at Post Graduation level.

Pallamreddy.venkatasubbareddy and Vuda Sreenivasarao (2010) [16] explained the Decision trees are commonly used in operations research, specifically in decision analysis, to help identify a strategy most likely to reach a goal and use of decision trees is as a descriptive means for calculating conditional probabilities.

\section{Data Mining Definition and Techniques}

Data mining refers to extracting or "mining" knowledge from large amounts of data [3]. Data mining techniques are used to operate on large volumes of data to discover hidden patterns and relationships helpful in decision making [1]. The sequences of steps identified in extracting knowledge from data are: shown in Figure 1.

Various algorithms and techniques like Classification,
Clustering, Regression, Artificial Intelligence, Neural Networks, Association Rules, Decision Trees, Genetic Algorithm, Nearest Neighbor method etc., are used for knowledge discovery from databases. These techniques and methods in data mining need brief mention to have better understanding.

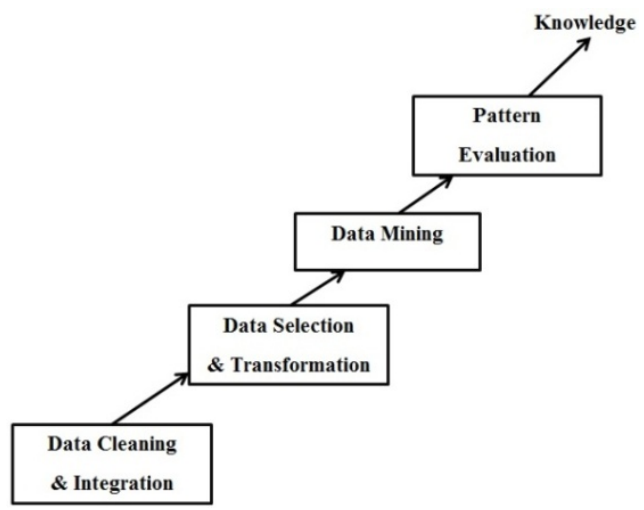

Figure 1. The Steps of Extracting Knowledge from Data

\subsection{Classification}

Classification is the most commonly applied data mining technique, which employs a set of pre-classified examples to develop a model that can classify the population of records at large. This approach frequently employs decision tree or neural network-based classification algorithms. The data classification process involves learning and classification. In Learning the training data are analyzed by classification algorithm. In classification test data are used to estimate the accuracy of the classification rules. If the accuracy is acceptable the rules can be applied to the new data tuples [1]. In our case study we used ID3 decision tree to represent logical rules of student final grade.

\subsection{Clustering}

Clustering is finding groups of objects such that the objects in one group will be similar to one another and different from the objects in another group. In educational data mining, clustering has been used to group students according to their behavior. According to clustering, clusters distinguish student's performance according to their behavior and activates. In this paper, students are clustered into three groups according to their academics, punctuality, exams and soon [8].

\subsection{Association rule}

Association analysis is the discovery of association rules showing attribute-value conditions that occur frequently together in a given set of data. Association analysis is widely used for market basket or transaction data analysis [9].

\subsection{Decision Trees}


Decision trees are commonly used in operations research, specifically in decision analysis, to help identify a strategy most likely to reach a goal [10].

\section{Data Mining Process}

\subsection{Data Preparations}

The data set used in this study was obtained from a student's database used in one of the educational institutions, on the sampling method of Information system department from session 2005 to 2010 . Initially size of the data is 1547 records. In this step data stored in different tables was joined in a single table after joining process errors were removed.

\subsection{Data selection and transformation}

In this step only those fields were selected which were required for data mining. A few derived variables were selected. While some of the information for the variables was extracted from the database. All the predictor and response variables which were derived from the database are given in Figure 2.

\begin{tabular}{|c|c|c|}
\hline Variable & Description & Possible Values \\
\hline Dep & Department of Students & $\begin{array}{l}\text { \{Literary, Scientific } \\
\text { Mathematics, Scientific } \\
\text { Science, Secondary } \\
\text { Industrial Technical, } \\
\text { Secondary Technical } \\
\text { Commercial\} }\end{array}$ \\
\hline HSD & $\begin{array}{l}\text { High School degree of } \\
\text { students }\end{array}$ & \{Good, Acceptable\} \\
\hline Midterm & Midterm Marks & $\begin{array}{l}\text { \{EXCELLENT }>-85 \% \\
\text { Very Good }>-75 \& \\
<85 \% \\
\text { Good }>-65 \&<75 \% \\
\text { Acceptable }>-50 \& \\
<65 \% \\
\text { Fail }<50 \%\}\end{array}$ \\
\hline LG & Lab Test Grade & \{Poor, Average, Good \\
\hline SEM & Seminar Performance & \{Poor, Average, Good \\
\hline ASS & Assignment & \{Yes, No\} \\
\hline SP & $\begin{array}{l}\text { Measure of Student } \\
\text { Participate }\end{array}$ & $\{$ Yes, No\} \\
\hline ATT & Attendance & \{Poor, Average, Good \\
\hline HW & Homework & $\{$ Yes, No $\}$ \\
\hline FG & Final Grade Marks & $\{$ EXCELLENT $>=85 \%$ \\
\hline
\end{tabular}

Figure 2. Student Related Variables

\subsection{Decision Tree}

A decision tree is a flow-chart-like tree structure, where each internal node is denoted by rectangles, and leaf nodes are denoted by ovals. All internal nodes have two or more child nodes. All internal nodes contain splits, which test the value of an expression of the attributes. Arcs from an internal node to its children are labeled with distinct outcomes of the test. Each leaf node has a class label associated with it [11].

\subsection{The ID3 Decision Tree}

The basic idea of ID3 algorithm is to construct the decision tree by employing a top-down, greedy search through the given sets to test each attribute at every tree node. In order to select the attribute that is most useful for classifying a given sets, we introduce a metric - information gain. To find an optimal way to classify a learning set we need some function which provides the most balanced splitting. The information gain metric is such a function. Given a data table that contains attributes and class of the attributes, we can measure homogeneity of the table based on the classes. The index used to measure degree of impurity is Entropy [2].

The Entropy is calculated as follows:

$$
\text { Entropy }=\sum_{j}-P_{j} \log _{2} P_{j}
$$

Splitting criteria used for splitting of nodes of the tree is Information gain. To determine the best attribute for a particular node in the tree we use the measure called Information Gain. The information gain, Gain (S, A) of an attribute $\mathrm{A}$, relative to a collection of examples $\mathrm{S}$, is defined as:

$$
\operatorname{Gain}(S, A)=\operatorname{Entropy}(\mathrm{S})-\sum_{v \in \text { Values }(A)} \frac{\left|S_{v}\right|}{|S|} \operatorname{Entropy}\left(S_{v}\right)
$$

\section{Results and Discussion}

The data set used in this study was obtained from a student's database used in one of the educational institutions, on the sampling method of Information system department from session 2005 to 2010 . Initially size of the data is 1548

\begin{tabular}{|c|c|c|c|c|c|c|c|c|c|c|}
\hline No.ST & Misterm & LG & SEM & ASS & SP & ATT & HW & FG & Dep & HSD \\
\hline $\mathrm{l}$ & Excellaet & Good & Good & Yes & Yes & Good & Yes & Excellent & Literary & Good \\
\hline 2 & Excellent & Good & Average & \begin{tabular}{|l|} 
Yes \\
\end{tabular} & No & Good & \begin{tabular}{|l|} 
Yes \\
\end{tabular} & Excellent & Literary & Acceptable \\
\hline 3 & Excellent & Good & Average & No & No & Averags & No & Excellent & $\begin{array}{c}\text { Scientific } \\
\text { Mathematics }\end{array}$ & Good \\
\hline 4 & Excetlest & Average & Good & No & No & Good & $Y_{\text {es }}$ & Excellent & $\begin{array}{c}\text { Scientific } \\
\text { Mathematies }\end{array}$ & Good \\
\hline 5 & Excolleat & Average & Averaye & No & Yes & Good & Yes & Excellent & $\begin{array}{c}\text { Scinetific } \\
\text { Mrthematics }\end{array}$ & Accoptable \\
\hline . & . & . & . &. &. & . &. & . & . & . \\
\hline
\end{tabular}
records are given in Figure 3.

Figure 3. Data Set

To work out the information gain for A relative to $\mathrm{S}$, we first need to calculate the entropy of S. Here $\mathrm{S}$ is a set of 1547 examples are 292 " Excellent ", 536 "Very Good", 477 "Good", 188 "Acceptable" and 54 "Fail".

$$
\begin{aligned}
\text { Entropy }(S) & = \\
& -P_{\text {Excellent }} \log _{2}\left(P_{\text {Excellent }}\right)-P_{\text {VeryGood }} \log _{2}\left(P_{\text {VeryGood }}\right) \\
& -P_{\text {Good }} \log _{2}\left(P_{\text {Good }}\right)-P_{\text {Acceptable }} \log _{2}\left(P_{\text {Acceptable }}\right) \\
& -P_{\text {Fail }} \log _{2}\left(P_{\text {Fail }}\right)
\end{aligned}
$$


To determine the best attribute for a particular node in the tree we use the measure called Information Gain. The information gain, Gain ( $\mathrm{S}, \mathrm{A})$ of an attribute $\mathrm{A}$, relative to a collection of sample $\mathrm{S}$.

$$
\begin{aligned}
\text { Gain }(S, \text { Midterm }) & =\text { Entropy }(S)- \\
& \frac{\left|S_{\text {Excellent }}\right|}{\left|S_{\text {Excellent }}\right|} \text { Entropy }\left(S_{\text {Excellent }}\right)-\frac{\left|S_{\text {VeryGood }}\right|}{\left|S_{\text {VeryGood }}\right|} \text { Entropy }\left(S_{\text {VeryGood }}\right)- \\
& \mid \frac{\left|S_{\text {Good }}\right|}{\left|S_{\text {Good }}\right|} \text { Entropy }\left(S_{\text {Good }}\right)-\frac{\left|S_{\text {Acceptable }}\right|}{\left|S_{\text {Acceptable }}\right|} \text { Entropy }\left(S_{\text {Acceptable }}\right)- \\
& \frac{\left|S_{\text {Fail }}\right|}{\left|S_{\text {Fail }}\right|} \text { Entropy }\left(S_{\text {Fail }}\right)
\end{aligned}
$$

Midterm has the highest gain, therefore it is used as the root node as shown in figure 4.

This process goes on until all data classified perfectly or run out of attributes. The knowledge represented by decision tree can be extracted and represented in the form of IF-THEN rules as shown in Table 1.

The Table 1 discusses 8 cases:

Case 1 - If Midterm Mark = Excellent, Lab Test Grade = Good, Student Participate $=$ No, Homework $=$ No, Seminar
Performance $=$ Good, Department $=$ Scientific Mathematics then Final Grade = Very Good.

Case 2 - If Midterm Marks $=$ Excellent, Lab Test Grade $=$ Good, Student Participate $=$ No, Attendance $=$ Good, Homework $=$ No, Department $=$ Secondary Technical Commercial then Final Grade $=$ Very Good.

Case 3 - If Midterm Marks = Excellent, Lab Test Grade = Good, Student Participate $=$ No, Attendance $=$ Good, Homework $=$ No, Department $=$ Secondary Industrial Technical then Final Grade = Very Good.

Case 4 - If Midterm Mark = Excellent, Lab Test Grade = Poor, Attendance $=$ Good then Final Grade $=$ Very Good.

Case 5 - If Midterm Mark = Excellent, Lab Test Grade = Average, Attendance $=$ Good then Final Grade $=$ Excellent.

Case 6 - If Midterm Mark = Excellent, Lab Test Grade = Average, Attendance $=$ Poor then Final Grade $=$ Very Good .

Case 7 - If Midterm Mark = Very Good, Lab Test Grade = Good, Homework $=$ No, Seminar Performance $=$ Good, Student Participate $=$ No then Final Grade $=$ Very Good .

Case 8 - If Midterm Mark = Very Good, Lab Test Grade = Good, Homework $=$ No, Seminar Performance $=$ Good, Student Participate $=$ No, Department $=$ Scientific Mathematics then Final Grade = Very Good.

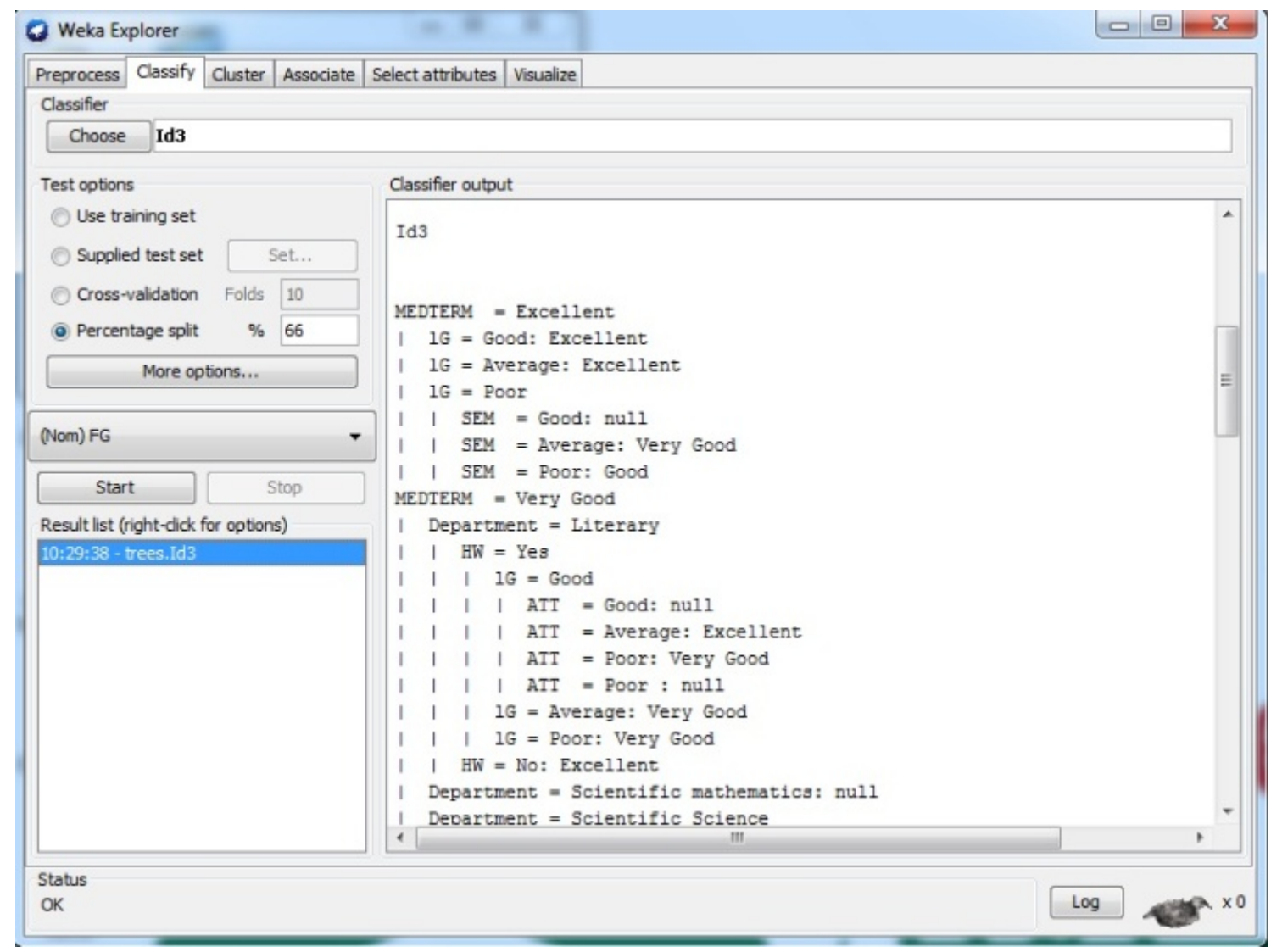

Figure 4. Midterm as root node 
Table 1. Rule Set generated by Decision Tree

\begin{tabular}{|c|}
\hline $\begin{array}{c}\text { IF Midterm='Excellent' AND LG='Good' AND SP='No' AND HW='No' AND SEM='Good' Dep='Scientific Mathematics' THEN } \\
\text { FG='Very Good' }\end{array}$ \\
\hline $\begin{array}{c}\text { IF Midterm='Excellent' AND LG='Good' AND SP='No' AND ATT='Good' AND HW='No' AND Dep=' Secondary Technical } \\
\text { Commercial' THEN FG='Very Good' }\end{array}$ \\
\hline $\begin{array}{r}\text { IF Midterm='Excellent' AND LG='Good' AND SP='No' AND ATT='Good' AND HW='No' AND Dep=' Secondary Industrial } \\
\text { Technical' THEN FG='Very Good' }\end{array}$ \\
\hline IF Midterm='Excellent' AND LG='Poor' AND ATT='Good' THEN FG='Very Good' \\
\hline IF Midterm='Excellent' AND LG='Average' AND ATT='Good' THEN FG='Excellent' \\
\hline IF Midterm='Excellent' AND LG='Average' AND ATT='Poor' THEN FG='Very Good' \\
\hline IF Midterm='Very Good' LG='Good' AND HW='No' AND SEM='Good' AND SP='No' THEN FG='Very Good' \\
\hline Matterm='Very Good' LG='Good' AND HW='No' AND SEM='Good' AND SP='No' AND Dep='Scientific \\
Mathematics' THEN FG='Very Good'
\end{tabular}

\section{Conclusion}

In this paper, decision tree method is used on student's database to predict the student's performance on the basis of student's database. We use some attribute were collected from the student's database to predict the final grade of student's.

This study will help the student's to improve the student's performance, to identify those students which needed special attention to reduce failing ration and taking appropriate action at right time.

\section{REFERENCES}

[1] Brijesh Kumar Baradwaj, Saurabh Pal, Data mining: machine learning, statistics, and databases, 1996.

[2] Nikhil Rajadhyax, Rudresh Shirwaikar, Data Mining on Educational Domain, 2012.

[3] Jiawei Han ,Micheline Kamber, Data Mining: Concepts and Techniques, 2nd edition, 2006.

[4] Alaa El-Halees, Mining Students Data to Analyze Learning Behavior: A Case Study, 2008.

[5] Mohammed M. Abu Tair, Alaa M. El-Halees, Mining Educational Data to Improve Students' Performance: A Case Study, 2012.
[6] Sonali Agarwal, G. N. Pandey, and M. D. Tiwari, Data Mining in Education: Data Classification and Decision Tree Approach, 2012.

[7] Monika Goyal ,Rajan Vohra2, Applications of Data Mining in Higher Education, 2012.

[8] P. Ajith, M.S.S.Sai, B. Tejaswi, Evaluation of Student Performance: An Outlier Detection Perspective, 2013.

[9] Varun Kumar, Anupama Chadha, An Empirical Study of the Applications of Data Mining Techniques in Higher Education, 2011.

[10] Hongjie Sun, Research on Student Learning Result System based on Data Mining, 2010.

[11] Surjeet Kumar Yadav, Brijesh Bharadwaj, and Saurabh Pal, Mining Education Data to Predict Student's Retention: A comparative Study, 2012.

[12] Brijesh Kumar Baradwaj, Saurabh Pal, Mining Educational Data to Analyze Students" Performance, 2011.

[13] K.Shanmuga Priya, A.V.Senthil Kumar, Improving the Student's Performance Using Educational Data Mining, 2013.

[14] Bhise R.B, Thorat S.S, Supekar A.K, Importance of Data Mining in Higher Education System, 2013.

[15] Varun Kumar, Anupama Chadha, Mining Association Rules in Student's Assessment Data, 2012.

[16] Pallamreddy.venkatasubbareddy, Vuda Sreenivasarao, The Result Oriented Process for Students Based On Distributed Data Mining, 2010. 